\title{
The Early History of the Levant Company (Levant Kumpanyası'nın Erken Dönem Tarihi), M. Epstein, George Routledge, Londra 1908, 270 sayfa.
}

Levant ticareti, Orta Çağ'da İtalya elinde olan Doğu mallarının Hristiyan dünyasına ulaşma imkânı bulduğu bir ticaret olarak ortaya çıkmıştır. Sonraki dönemlerde, İngiliz hegemonyasına giren bu ticareti, etkin olan tüccarlar bağlamında incelemek Levant ticaretinin ilk dönemlerini anlamak noktasında geniş bir perspektif sağlayacaktır. M. Epstein'in 1908 yılında kaleme aldığı The Early History of The Levant Company (Levant Kumpanyası'nın Erken Dönem Tarihi) kitabı, konuyu iki ana dönem de on bir başlık altında inceleyerek bu ticaretin kapsamını ortaya koymuştur. Kitabın ilk bölümü içerisinde erken dönemde (1592-1605) kurulan ve bölgesel üstünlüklere dayalı olarak ticaret yapan Türkiye, Kumpanyası ve Levant Kumpanyaları değerlendirilmiştir. Kitabın ikinci bölümünde ise Levant ticaretini 1640 yılına kadar kalıc ticari üstünlükler ve imtiyazlar gibi birçok unsuru göz önüne alarak değerlendirmiştir. Dr. Epstein'in bu çalışması hem dönemi çalışan tarih araştırmacılarına mahkeme tutanakları, mektuplar ve liman/gemi bilgileri gibi orijinal belgelerle Levant ticaretinin doğasını ve işleyişini anlama imkanı sunarken hem de dönemin uluslararası ilişkilerini siyasi tarih çerçevesinden anlama imkanı sunmaktadır. Bir asırdan önce kaleme alınmış olan bu eser özellikle ülkemizde Levant konusunu çalışan kişilere, dönemin Osmanlı kaynaklarına ek olarak İngiliz kaynaklarının da kapılarını açmıştır. Çalışma bu açıdan bakıldığında Levant Kumpanyası'nın ticari hacmine ek olarak bu ticaretin dünya siyasetine ne derece damga vurduğunu da ilgili ülkelerin arşivlerini kullanarak ortaya koymuştur. Ekonomik servet olarak tanımlanan ve devletlerin ellerinde tuttukları altın ve gümüş gibi değerli madenlerin, diğer devletlerle olan ticari ilişkilerle sağlanması/biriktirilmesi konusunun altını çizen merkantalizmin de bir anlamda temelleri bu çalışmada görülebilmektedir. Kısacası bahsi geçen bu çalışma, hem ekonomik ve ticari hareketleri hem de siyasi ve diplomatik adımları arşiv belgeleriyle harmanlayarak Tarih, Ekonomi ve Uluslararası İlişkiler alanlarında 16.yy ve sonrası dönemlerini çalışanlar için günümüzde bile önemini koruyan bir başyapıt niteliğindedir.

Kitabın giriş bölümünde 1581 yılına kadar olan ticari eğilimlerden ve dönüşümlerden bahsedilmektedir. Bu dönemde İngiltere ve Venedik arasında ticareti şekillendiren "Flanders Galleys" adındaki küçük bir filonun İngiltere'ye getirdiği ticari mallar sınıflandırılmış ve iki gruba ayrılmıştır. ilk grup dönemin ticaretine ağırlığını koyan baharatlar ve ikinci grup ise Doğu'dan getirilen genel kullanıma yönelik ürünler ve Venedik'ten getirilen mallar olarak belirtilmiştir (s.23). Fakat, 8. Henry'nin İngiliz gemilerinin şarap ticaretinde üstünlük kurmasını 
arzulayan yaklaşımlarını desteklemek amacıyla uyguladığı ticaret ve denizcilik politikaları nedeniyle Venedik'in İngiltere ile olan ticareti gerilemeye başlamıştır. 1532 yılında ticarete yön veren filo son kez Southampton limanından demir almıștır. Yine de bu durum iki devlet arasındaki ticaretin sonunu getirememiștir. Venedikli tüccarlar Akdeniz mallarını doğabilecek tüm riskleri kendileri üstlenerek İngiltere'ye götürmeye devam etmişleridir. Bu riskli ticaret ise Ekim 1587 yılında bir Venedik gemisinin batmasıyla son bulmuştur. Bu süreç içerisinde İngiltere, Sicilya, Girit (Candia) ve Sakız (Chios) adalarına ticarete başlamış olmasına rağmen Levant İngiliz denizciler için bir muamma şeklinde kalmış ve keşfedilmesi için biraz daha zamana ihtiyaç duyulmuştur. 1500'lü yılların ortalarına gelindiğinde Akdeniz ticaretinde İngilizler, Venedikli denizcilerden daha uygun fiyata ticaret yapabildikleri için ön plana çıkmaya başlamışlardır. İngilizlerin bu ticari atağı süresince Osmanlı Devleti ile ilk karşılaşması Anthony Jenkinson adındaki seyyahın 1553 yılında Halep'te Kanuni Sultan Süleyman tarafından verilen ticari haklar ile olmuştur. Bu haklar Jenkinson'a Venedikli ve Fransız tüccarlarla aynı şekilde ticaret yapma olanağı sağlamıştır. İngiliz tüccarın Osmanlı Devleti'nde yapmış olduğu bu ticaret 1575 yılına kadar bireysel olarak devam etmiştir. 1578 yılında ise Sultan'dan alınan bir ticaret serbestisiyle William Harborne İstanbul'a ulaşmıştır. Harborne, yetenekli bir tüccar olmasının yanı sıra diplomat olarak da çalışmış ve sultandan Kraliçe Elizabeth'e yazılan bir mektup götürerek iki devlet arasında imtiyazlı bir ticaretin başlamasına vesile olmuştur. Sultan III. Murat Haziran 1580 yılında İngiliz tüccarları Avrupalı tüccarlarla aynı seviyeye getiren imtiyazları onaylamıştır.

Kitabın ikinci bölümünde de, Akdeniz ticaretinde Avrupalıların yanında İngilizlerin de güç kazanmasına sebep olan İngilizler ve Osmanlı arasındaki imtiyazlar konu edilmiştir (s.16). Sultan'ın imtiyazları ile başlayan ticaret serbestisi yedi yıllık bir dönemi kapsamaktaydı. Bu bağlamda 11 Eylül 1581 tarihinde Osmanlı ya da Türkiye Kumpanyası kurulmuştur. Ancak ticaret beklendiği gibi karlı olursa ikinci bir yedi yıllık imtiyaz hakkının verileceğine dair şerh konulmuştur. Yedi yıllık sürecin altısında yıllık 500 Sterlinin altında ticaret yapılamayacağına dair de bir şart konulmuştur. Osmanlı imtiyazlarında gemi adedi ve sınırı da getirdiğinden İngilizler özel durumlarda gemi adedine dair verilmiş olunan izni genişletmek istemişlerdir. Kitapta, Osmanlı-İngiliz ticaretine konu olan mallardan da bahsedilerek, İngilizlerin Osmanlı'dan baharat, pamuk, ham ipek, üzüm ve sabun aldığından, Osmanlının ise kıyafetler, şayak, boyanmış ve tabaklanmış tavşan derisi aldığından bahsedilmiştir. Osmanlı-İngiliz ticaretinin ilk beş yıllık değerlendirmesine değinen (s.19) kitap, bu süreçte 19 geminin 27 sefer yaptığından bu seferlerde 787 denizcinin çalıștığından ve toplam 11,358 Sterlinlik bir ticaret yapıldığından bahsetmiştir.

Kitabın üçüncü bölümünde İngilizlerin Osmanlı ticareti için kurdukları kumpanyanın yanı sıra Venedik ile olan ticareti yöneten kumpanyadan (Venice Company) bahsedilmiştir. Bu bağlamda, 1575 yılında Kraliçe Elizabeth'in Floransalı Acerbo Velutelli adına verdiği frenk üzümü ticareti için bir imtiyazdan 
bahsedilmiştir (s.20). Bu dönemde İspanya'nın uyguladığı ambargo neticesiyle İngiliz tüccarlar İspanya ticaretinden çekilmek zorunda kalmışlardır. Bunun üzerine İngilizler Akdeniz'den frenk üzümü ticaretine devam etmişlerdir. Fakat ortaya çıkan memnuniyetsizlik Kraliçeye yansımış ve tüm yabancı tüccarlar ticaret lisansları için ödeme yapmak zorunda bırakılmışlardır. Bunun yansıması olarak Venedik de aynı şekilde bir uygulamaya gitmiş ve yabancı tüccarlar ağır ödemelerle karşı karşıya bırakılmışlardır. Sürecin sonrasında, Kraliçe bazı İngiliz tüccarlara Venedik'e ticaret yapma ayrıcalığı tanımıştır. Bu ayrıcalık Edward Cordell, Edward Hambdon, Paul Banning ve diğerlerine Venedik'ten frenk üzümü, tatlı şarap ve zeytinyağı getirebileceklerine dairdir. Bu tüccarların dahil olduğu kumpanya haricinde İngiltere'ye bu ürünleri sokmak isteyenlere de Kumpanya ağır vergiler uygulamıştır.

Kitabın dördüncü bölümünde Akdeniz ticaretine damgasını vuran Levant Kumpanyası'nın kuruluşundan bahsedilmektedir. Önceki bölümlerde bahsedilen özellikle Venedikli ve İngiliz tüccarlar arasında ortaya çıkan ve ticareti sekteye uğratan problemler ve 1588 yılında Osmanlı'nın tanımış olduğu imtiyazların yenilenmemesi üzerine bazı tüccarların ümitleri kırılmıştır. Hem Osmanlı ile ticaret yapan (Turkey Company) hem de Venedik ile ticaret yapan (Venice Company) tüccarlar aynı ya da benzer malların ticaretini yapmakta, farklı vergilendirmelere maruz kalmakta ve coğrafi olarak birbirlerine çok yakın konumlanmak zorunda kalmaktaydı. Bunun üzerine İngiliz Hazine Bakanı bu iki kumpanyayı birleştirmekten ve tek bir yapı altında toplamaktan bahsetmiştir. Her iki kumpanyanın kendilerine ait imtiyazlarının sona ermesi ile beraber Levant Kumpanyası (The Governer and Company of Merchants of the Levant) 53 tüccarın katılımıyla 7 Ocak 1592 yılında kurulmuştur ve Levant Kampanyası'nın ilk yöneticisi Sir Richard Osborne olmuştur (s.36). Tek çatı altında birleşen kumpanyalar Osmanlı'nın hakimiyeti altındaki bölgeleri tekellerine almışlardır. Bu bölgeler, Venedik ve hatta Zante, Kefalonya ve Girit diğer bir değişle de Levant'ı yani Akdeniz'i ifade etmektedir. Daha sonraları, Levant ticaretinin kapsama alanı Güney Asya'yı bile kapsar hale gelmiştir. Levant Kumpanyası 12 yıllık bir tekel hakkı ile kurulmuş ve üyesi olan tüccarlara gümrük vergileri veya silahlanma gibi avantajlar sağlamıştır. Bu kumpanya ile ilgili olarak karlı olmadığına dair bir fikir ortaya çıkarsa 18 aylık bir bildirimin ardından kumpanya fesih edilebilir, eğer karlı olduğu ortaya çıkarsa 12 yıllık tekel olma hakkı 12 yıl daha uzatılabilirdi (s.39).

Kitabın iki ana bölümünün ilki altındaki son bölümde ise Levant Kumpanyası'nın ilk tekel dönemi değerlendirilmiştir. Kumpanya içerisindeki tüccarlara tanınmış olan haklar, ticaretin yoğun yapıldığı mallardan olan şarap ve kuru üzüm gibi malların fiyatlarını arttırmıştır. Dr. Epstein konu ile ilgili olarak "Türklerle ilişkinin sürdürülmesi için gerekli gözlemler" adlı bir belgede mevcut tüccarlara yeni tüccarlar eklenmesinin neredeyse imkansız olduğuna dair yapılan açıklamaya da atıf yaparak karlılık durumunu göstermiştir. Kumpanya Ingiltere'ye sokulan her 100 librelik frenk üzümü için yabancılardan ve kumpanyaya dahil olmayan İngilizlerden 5 Şilin 6 Peni aldığı için kendini popüler olmaktan çok uzak 
bir yere konumlandırmıştır. Yükselen şikayetler üzerine Kraliçe vermiş olduğu imtiyazları geri çekmiştir ve Kumpanya'nın kurulmasını sağlayan tüm haklar hükümsüz kılınarak tüccarların Levant içerisinde ticaret yapması durdurulmuştur. Kaybedilen bu imtiyazın üzerine 12 Temmuz 1600 tarihinde Kraliçeye bir dilekçe yazılarak ellerinden alınan ayrıcalıkları geri talep eden tüccarlar, bu haklarına Kraliçeye ödeme yapmaya dair söz verdikten sonra 31 Aralık 1601 tarihinde 15 yıllığına kavuşmuşlardır (s.46). Fakat bu ayrıcalıkları I.James tahta çıkana kadar yani sadece iki yıl kullanabilmişlerdir. 31 Ekim 1603 yılında Kral, kumpanyadan gelen yıllık 4000 sterlinlik ödemeyi alamamasından dolayı gelir kaybına uğradığını düşünerek hazine bakanlığına yeni vergiler getirilmesini emretmiş ve bu vergilerin ve ödemelerin tüccarların mallarından değil doğrudan kiralarından alınmasını emretmiştir. Rahatsızlık büyümüş ve Kral ile anlaşma yoluna gidilmiş fakat Kral "ticaret hacminin kendisine yapılacak ödemeleri rahatlıkla kaldırabileceğini” söyleyerek anlaşmaya yanaşmamıştır. Bu süreç içerisinde tüccarlar düzensizlikten, Venedikli tüccarlarla rekabetten ve yeni kurulmuş olan Doğu Hindistan Kumpanyasın'dan mustarip hale gelmişlerdir. Richard Straper 8 Temmuz 1605 yılında yazmış olduğu mektupta Levant ticaretinin devam etmesi gerektiğini ısrarla vurgulamıştır. Bu durumun ticari bir gelir kaybından ziyade 1588 de olduğu gibi siyasi bir kayıp olabileceği konusuna da vurgu yapmıştır. Yapılan bu değerlendirmeler ve ticaretin hem maddi hem de siyasi getirilerinin göz önüne alınmasının ardından, Kral tekelciliği reddederek 14 Aralık 1605 yılında Levant Kumpanyası için yeni bir başlangıca müsaade etmiştir. Halen kısaca Levant Kumpanyası olarak kullanılan isim ise (The Governer and Company of Merchants of England trading into the Levant Seas) olarak değiștirilmiş ve Akdeniz de ticaret yapan İngiliz tüccarlar vurgusu yapılmıştır. Bu bağlamda bakıldığında, Kumpanyanın getirdiği ayrıcalıklardan sadece İngiliz tüccarlar yararlanabilmektedir.

Kitabın ikinci bölümünde, Dr. Epstein, Levant Kumpanyası'nın 1605 yılında başlayan ikinci dönemine dair beş başlık altında değerlendirmeler yapmıştır. Bu değerlendirmelerin kapsamı ticarete konu olan mallar, ticaretin düzenlenmesine dair kurallar, tüccarların yıllık toplantıları, kumpanyada görevli kişiler ve ticareti sekteye uğratan simsarlar, korsanlar ve yetkisiz tüccarlardır. 1605 yılında Kumpanya kalıcı bir sözleşmeye kavuşunca, 200 yıldan daha uzun bir süre bu sözleşmeyle yönetilebilmiş ve 1825 yılında Kumpanya'nın faaliyetleri sonlandırılmıştır. İkinci bölümün ilk içeriği, bu süreç içerisinde özellikle 1640 yılına kadar olan dönemde Levant Kumpanyası'nda görevli personel hakkında olmuştur. Kumpanyada görevli olanlar, toplantı tutanakları (the Court Books) içerisinde detaylı olarak belirtilmiştir. Bunlara göre kumpanya da görevli kişiler, yönetici/vali (the Governor), yönetici/vali yardımcısı (Deputy Governor), hazine (treasurer), arşiv personeli-aynı zamanda gemilerin ve malların kaydını tutan kişi (husband), sekreter (secretary), sayman (bookkeeper), mübaşir (beadle), ve sonraki dönemde ise yıllık seçilen gözlemciler (auditors) olarak sıralanmıştır (s.68-69). Kumpanyanın görevlileri işlerini merkezden yürütürken sonraları temsil 
ettikleri bölgelerde de temsilci bulundurmuşlardır. Bu temsilciler, tercümanlar, hazine görevlileri ve vaizlerden oluşmaktadır. Örnek olarak, İstanbul'a, Halep'e ve İzmir'e vaizler gönderilmiştir. Kitabın önceki bölümlerinde de bahsedildiği gibi ticari aktiviteler aynı zamanda siyasi kimliklere de sahiptir. Bu bağlamda, İstanbul'a gelen büyükelçiler kumpanyanın menfaatlerini gözeten diplomatik ajanlar olarak konumlanmışlardır (s.76). Bu süreçte Osmanlı tarafından diplomatik temsilcilerin aynı zamanda tüccarların menfaatine çalışıldığı öğrenilirse mallarına el konulacağını bilen Kumpanya büyükelçileri kendi belirlemeye başlamıştır. Bu durum hem kumpanya içerisinde taraftarlık konusunda problemler doğurmuş hem de Osmanlı Devleti'nin bu durumu anlamasından duyulan endişe artmıştır. Nihayetinde 13 Nisan 1632 yılında İstanbul'da bulunan büyükelçinin hiçbir malın ticaretiyle doğrudan veya dolaylı olarak ilgilenemeyeceği belirtilmiştir. Aynı döneme denk gelen bir başka sorun ise kumpanyaya konsolos/konsül atanması olmuştur. Kral 1. Charles konsülleri kendi atamaya başlamıştır. 2 Aralık 1633 yılında İzmir konsülü kendi adına veya başkası adına ticaret yapmama kuralıyla yıllık 1200 dolar maaşla Kral tarafından görevlendirilmiştir. Konsüllere ödenen maaşlarla ilgili kesin bir düzenleme bulunmamaktadır. Konuya Dr. Epstein, Patras konsülü Humphrey Bunnington örnek vererek Bunnington'un tüm giderleri kumpanya tarafından karşılanırken aynı zamanda Patras'a giren ve çıkan tüm ürünlerden \%2 oranında konsül vergisi alma yetkisinin olduğunun altını çizmiştir. (s.97).

Kitabın yedinci başı̆̆ı̆ı olan kumpanyanın toplantıları ve üyelik konusu

kitabın ikinci bölümünün de ikinci başlığıdır. Kumpanyanın yönetim kurulu toplantısı mahiyetinde olan Meeting of the Court düzenli aralıkla toplanmamıştır. Hatta Ekim 1622 yılında kumpanyadaki bu düzensiz toplanma konusunun hem ticarete hem de yönetime dair sorunlara neden olmasından ötürü cezai yaptırım fikri ortaya atılmışır. Bu bağlamda 3 Şubat 1629 yılının toplantı tutanaklarında, toplantılara katılmayanlara para cezası verilmesi yönünde ki karar görülmektedir. Toplantılar kural olarak valinin evinde yapılmıştır. Kumpanyanın üyeleri ticaret yapmakla ilgili sahip oldukları ayrıcalıkları yeni tüccarlarla paylaşmak konusunda her zaman isteksiz olmuşlardır. Bu sebepten ötürü, aslında kumpanyanın kurucu sözleşmesinde 25 Sterlin giriş ücreti veren herkesi kumpanyaya dahil olabileceğine dair kural bir çok kez göz ardı edilmiştir.

Bölümün üçüncü başlığı ise Levant ticaretinin ana mallarından biri olan frenk üzümünün ticareti ve ticarete konu olan diğer malların ticareti üzerinedir. Kitabın bu başlığı altında, Dr. Epstein kumpanyanın asıl amacının ve niyetinin ticarette tekel olmak olduğunun altını çizmiştir (s.109). Bu noktada yazar bu başlık altında yetkisiz tüccarların ticari tekel olma çabası içinde olan kumpanyaya verdiği ticari zararların da altını çizmiştir. Bu dönemde, frenk üzümü konusunda ticaret yapan kökenleri 1400'lü yıllara dayanan Tüccar Maceraperestler Kumpanyası (Company of Mercant Adventurers) da etkinliğini arttırmaya başlamıştır. İki kumpanyanın-Tüccar Maceraperestler Kumpanyası ve Levant Kumpanyası- da valisi olan Sir Thomas Lowe özellikle Almanya'dan ve Belçika'nın 
Flaman Bölgesi olan Fladers'ten frenk üzümü ithalini yasaklamıştır. Bu dönemde ve genel olarak her dönemde yetkisiz tüccarlardan kaynaklanan sorunlar ortaya çıkmıştır fakat buna ek olarak kumpanyanın üyesi olan tüccarlar da düzenlemelerden veya fiyatlandırmadan kaçmak için sık sık hilelere başvurmuştur. Hileli durumların tespitinde kumpanya gemi üzerindeki mallara el koyarak bir caydırıcılık ortaya koymuştur. Bir diğer düzenleme olarak tüccarların kat edecekleri mil başına ağırlık miktarına verilecek maksimum tutarlar belirlenmiştir. Bunun sebebi olarak ise hem iç piyasada hem de dış piyasada frenk üzümünün fiyatını büyük ölçüde sabitleyebilmektir (s.120). Bu bahsedilen düzenlemelerin kontrolünün sağlanabilmesi için Zante'de özel bir görevli bulundurulacak ve bu kişinin görevleri ise piyasanın ihtiyaçlarını belirlemek, pazarın kaydını tutmak ve frenk üzüm fiyatını gözlemlemek olarak listelenmiştir. 1638 yılında, ticaretin düzen içerisinde işlemesine yönelik, yıllık alış veriş zamanları, depolama, fiyatlandırma, sınırlandırma gibi düzenlemeler yapılmıştır (s.127-128). Ticaretin temel ürünü frenk üzümü olsa bile kimyasallar, deri, ipek, zeytinyağı, şarap gibi pek çok ürünün kumpanyada ki tüccarlar tarafın ticarete konu edilmişlerdi. Ve hatta, kıyafet ve mısır ticaretleri de düzenlemelere konu edilmiştir. Hatta, Sultan, mısırın sadece özel bir ayrıcalık olarak ihracatına izin vermiştir.

Bölümün dördüncü başlığı ise denizcilikle ilgili düzenlemeleri konu etmiştir. Kumpanya sadece gemilerin yelken açabileceği zamana karar vermekle değil aynı zamanda da gemilerin her seferinde navlun ücretlerini de belirlemiştir. 1631 tarihine kadar farklı ürünler için farklı ücretler belirlenmiş olsa da bu tarihten itibaren her gemi gidiş-geliş yolculuğu için ton başına toplamda 10 sterlin ödemiştir. Ödemelere ek olarak, yolculukların ne kadar sürmesi gerektiğine dair de düzenlemeler yapılmıştır. 1637 yılında müşterilerin Royal Exchange adlı gemiyi tehlikeli olarak nitelendirip ticaret yapmaktan çekinmeleri Kumpanyanın gelecekte ticarete dahil olacak gemileri denetleme kararı almasına neden olmuştur.

Bölümün son başlığı ise deniz ticaretini tehlikeye sokan simsarlar, korsanlar ve ticarette karın düşmesine sebep olan yetkisiz tüccarlardır. Yetkisiz tüccarlar, kumpanyaya üye olmayan fakat üyelerin sahip olduğu ayrıcalıklardan faydalanmak isteyen tüccarlardır. Dr. Epstein bu tüccarları tarif ederken "kaçakçı" ifadesini kullanmıştır (s.142). Kumpanyaya üye olmak tüccarlara ayrıcalık kazandırmaktaydı. Bu ayrıcalıklar hem ticaretin serbestçe yapılmasını hem de gemilerin güvenliğini kapsamaktaydı. İște bu noktada Akdeniz ticaretinin başlangıcından beri sorun olan korsanlığa karşı kumpanyaya üye olmayanlar koruma altında değillerdir. Bu dönem için korsanlar ve yetkisiz tüccarlar kumpanya için sürekli var olan meselelerdir, ancak buna rağmen Doğu'daki simsarlar kadar Kumpanyayı rahatsız etmemişlerdir. Simsarlar şirket üyelerinin Levant ticareti içerisindeki ajanlarıydılar ve patronları adına iş yapmak için oradaydılar. Fakat bu kişiler kendi hesaplarına iş yapmak gibi bir eğilimin içinde 
olmuşlardır. Kumpanya bu duruma engel olmaya çalışsa bile güçsüz ve yetersiz düzenlemelerle bu sorun ile baş edememiştir (s. 148).

Kitabın ana bölümlerinin ardından kitap içerisinde geniş bir "ekler" bölümü bulunmaktadır. Yazar burada, 1605 yılında kumpanyayı yeniden şekillendiren sözleşmeyi, kumpanyanın valilerini, büyükelçileri, konsülleri ve yardımcılarını, ticarete katılmış gemileri ve ticaretin yapıldığı limanları, vergileri ve dönem içerisinde yazılmış muhtelif belgeleri okuyuculara ve araştırmacılara kaynak olarak sunmuştur. Kitap, sade bir dil ile kaleme alınmış ve ilk elden arşiv kaynakları kullanarak konuları dönemin siyasi ve ticari konjonktürüne göre ele almıştır. İçerik bakımından da esere baktığımızda başta da bahsedildiği gibi bu eser, Osmanlı-Ingiliz ilişkileri başta olmak üzere Akdeniz ticaretine dahil olan veya olmak isteyen her devletin ilişkiler ağını, dönem içerisinde yapılan ticari ve diplomatik sözleşmeleri ve dönemin ticaretle bağlantılı olarak şekillenen politikalarını ortaya koyduğu için hem tarih okumalarında hem de uluslararası ilişkiler okumalarında bir başucu kaynağı niteliğindedir. 1908 yılında ilk olarak yayınlanan bu kitap 2015 yılında Routledge tarafından yeniden yayınlanmıştır (ISBN-13: 978-0678004166).

Dr. Öğr. Üyesi Furkan YILDIZ, Kırklareli Üniversitesi Sosyal Bilimler Meslek Yüksekokulu Dış Ticaret Bölümü, furkanyildiz1985@hotmail.com, ORCID ID: 0000-0003-1533-222X. 